Article

\title{
Susceptibility and Lethality of Western Equine Encephalitis Virus in Balb/c Mice When Infected by the Aerosol Route
}

\author{
Amanda L. Phelps ${ }^{1, *}$, Lyn M. O'Brien ${ }^{1}$, Lin S. Eastaugh ${ }^{1}$, Carwyn Davies ${ }^{1}$, Mark S. Lever ${ }^{1}$, \\ Jane Ennis ${ }^{2}$, Larry Zeitlin ${ }^{2}$, Alejandro Nunez ${ }^{3}$ and David O. Ulaeto ${ }^{1}$ \\ 1 CBR Division, Defence Science and Technology Laboratory (Dstl), Room 201, Building 7a, Porton Down, \\ Salisbury, Wiltshire SP4 0JQ, UK; lmobrien@dstl.gov.uk (L.M.O.); lseastaugh@dstl.gov.uk (L.S.E.); \\ cdavies@dstl.gov.uk (C.D.); mslever@dstl.gov.uk (M.S.L.); dulaeto@dstl.gov.uk (D.O.U.) \\ 2 Mapp Biopharmaceutical Inc., 6160 Lusk Blvd. \#C105, San Diego, CA 92121, USA; \\ jane.ennis@mappbio.com (J.E.); larry.zeitlin@mappbio.com (L.Z.) \\ 3 Pathology Department, Animal and Plant Health Agency, Weybrige, Woodham Lane, New Haw, \\ Addlestone, Surrey, KT15 3NB, UK; Alejandro.nunez@apha.gsi.gov.uk \\ * Correspondence: alphelps@dstl.gov.uk; Tel.: +44-1980-955365
}

Academic Editor: Curt Hagedorn

Received: 8 May 2017; Accepted: 20 June 2017; Published: 27 June 2017

\begin{abstract}
Western equine encephalitis virus (WEEV) naturally cycles between mosquitos and birds or rodents, with a case fatality rate of up to $15 \%$ in humans during epizootic outbreaks. There are no medical countermeasures to treat WEEV infection, and accidental aerosol exposure increases the case fatality rate up to $40 \%$. Understanding the pathogenesis of infection is required to develop and assess medical countermeasures. This study describes the clinical and pathological findings of mice infected with WEEV by the aerosol route, and use as a model for WEEV infection in humans. Balb/c mice were infected by the aerosol route with a dose range of high-virulence WEEV strain Fleming to establish the median lethal dose (MLD). The disease course was acute, culminating in severe clinical signs, neuroinvasion, and dose-dependent mortality. Further groups of mice were exposed by the aerosol route, periodically sacrificed, and tissues excised for histopathological examination and virology. Viral titres peaked four days post-challenge in the brain and lungs, corresponding with severe bilateral lesions in rostroventral regions of the encephalon, especially in the olfactory bulb and piriform cortex. Recapitulation of the most serious clinical presentations of human WEEV disease in mice may prove a useful tool in the evaluation of medical countermeasures.
\end{abstract}

Keywords: alphavirus; western equine encephalitis virus; WEEV; pathogenicity; median lethal dose (MLD); mouse; aerosol

\section{Introduction}

Western equine encephalitis virus (WEEV) is a member of the alphavirus genus of the family Togaviridae. Alphaviruses, Venezuelan equine encephalitis virus (VEEV), Eastern equine encephalitis virus (EEEV), and WEEV are grouped geographically as New World viruses capable of causing disease in both equids and humans, exhibiting overt encephalitic features in a significant number of cases. WEEV causes periodic epizootic outbreaks in Western and Central North America and is maintained in an enzootic cycle between mosquitos and birds or rodents [1] Humans are usually infected as a result of close proximity to infected equines and by being bitten by an infected mosquito. In humans, WEEV infections are generally asymptomatic but may result in the onset of flu-like symptoms; fever, malaise, headaches, vomiting, and nausea. In a minority of cases, symptoms progress to weakness, confusion, seizures, and encephalitis, and may lead to coma and death. The case fatality 
rate is typically $3-4 \%$, when infection is acquired from a natural enzootic cycle, particularly affecting infants and the elderly [2]. Survivors of WEEV infection can be left with persisting neurological sequelae, requiring significant healthcare intervention [3-5]. During epizootic outbreaks, the case fatality rate is reported to rise to $8-15 \%$ [6], and after accidental laboratory exposures to WEEV by the aerosol route it has been documented to be as high as $40 \%(2 / 5)$ [7]. Exposure by the aerosol route may facilitate neuroinvasion of WEEV, potentially the cause of a marked increase in mortality, and is in-part why WEEV is considered a potential biothreat agent [8]. WEEV, as well as VEEV and EEEV, are listed as Category B agents by the National Institute of Allergy and Infectious Diseases, and the Centre for Disease Control $[9,10]$. Additionally, there are currently no licensed vaccines or antiviral therapies for the prevention or treatment of these viruses in humans. WEEV is therefore of significant concern in relation to both natural outbreaks and its potential use as a biothreat agent. Research directed at characterizing appropriate models of disease, understanding the pathogenesis of infection and ultimately identifying effective medical countermeasures to WEEV is required. The use of in vivo models is currently the most effective holistic approach to understanding the outcome or effect of medical countermeasures, offering well-defined experimental parameters. As with many in vivo models of human disease, a small animal model is very often the foundation for non-human primate studies, and progressively, human clinical trials.

A small number of studies have previously investigated rodents and non-human primates [11] as models of WEEV infection and disease. In hamsters, the intranasal or intraperitoneal routes of infection were lethal with rapid neuroinvasion, and peak viral titres were observed in key tissues between 2-4 days post-challenge [12]. A number of mouse strains have been investigated, utilizing both in-bred and out-bred strains of different ages and genders, and with parenteral and aerosol routes of exposure. Early investigations examined the use of Swiss Rockefeller and National Institute of Health Swiss mice and demonstrated age-dependent susceptibility [13,14]. More recently, detailed host factor assessments confirmed the importance of age on susceptibility to WEEV in mice and also demonstrated that gender and genetic background of the host were important factors for survival [15]. As well as host factors, the route, virulence, and dose of virus also influences the outcome of infection. High- and low-virulence WEEV strains have been reported to infect Balb/c, C57BL/6, and CD1 mice, although spread to the central nervous system, severity of overt neurological signs, and mortality depended on the dose of virus and the route of exposure [16-20].

The known hazard to humans from aerosol infection necessitates a model that uses this route. However, studies often use intra-nasal inoculation as a surrogate for aerosol exposure. In a recent study examining the clinical course of a closely-related Alphavirus, EEEV, adult Balb/c mice were infected by the intra-nasal and aerosol routes, yielding $100 \%$ lethality, with rapid neuroinvasion and acute onset of clinical signs [21]. In this study, a number of parameters were comparable between the two exposure routes (weight, clinical scores, cytokine expression), although importantly, virus was detected in the brain of aerosol exposed mice at $6 \mathrm{~h}$ post-infection. In contrast, virus was not detected in the brain of intra-nasally exposed mice until $24 \mathrm{~h}$ post-infection. Such rapid neuroinvasion suggests that aerosol exposure may induce a precipitous onset of encephalitic disease. In this report, the course of WEEV infection in adult Balb/c mice exposed by the aerosol route is presented. This includes viral load and distribution, establishing a clinical scoring system and determination of the Median Lethal Dose (MLD), as well as histopathological and immuno-histochemistry findings.

\section{Results}

\subsection{Viability of Western Equine Encephalitis Virus Fleming in an Aerosol}

Three independent experiments were undertaken to assess the viability of WEEV Fleming following aerosolisation in the AeroMP aerosol apparatus (Biaera Technologies, LLC, Hagerstown, MD, USA). The relationship between input virus (Collison) and output virus (Impinger) is shown in Figure 1. There was a linear relationship between data sets with a mean difference of $3.4 \log _{10}$ plaque forming 
units $/ \mathrm{mL}(\mathrm{pfu} / \mathrm{mL}$ ) between input and output virus titres. These data are consistent with equivalent data produced using the closely related alphavirus, VEEV, when aerosolised (data not shown).

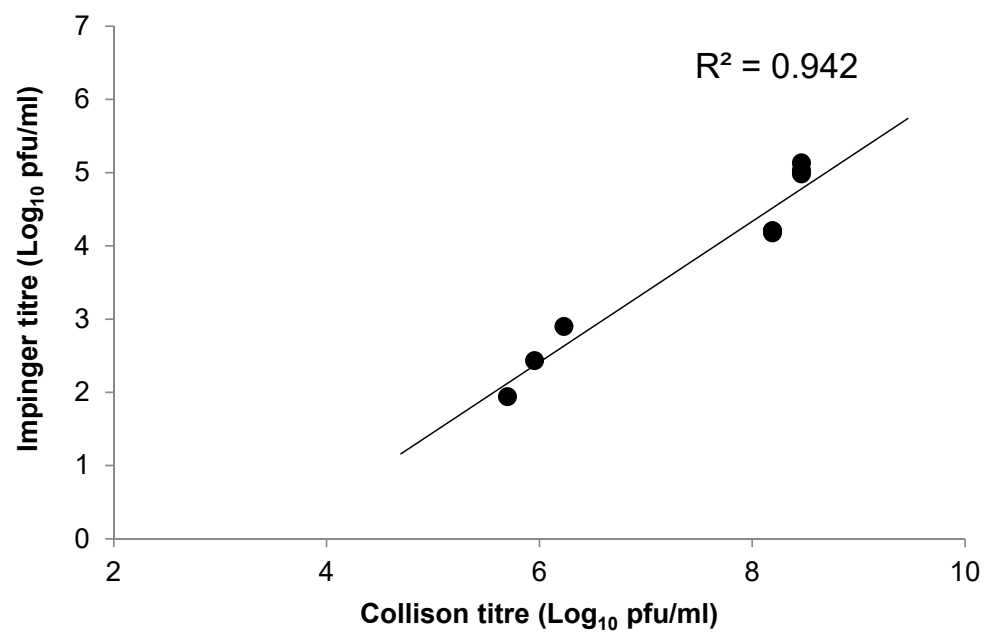

Figure 1. Relationship between input (Collison) and output (Impinger) virus titres of Western equine encephalitis virus (WEEV) Fleming when aerosolised using an AeroMP platform system. $n=3$.

\subsection{Median Lethal Dose of Western Equine Encephalitis Virus Fleming by the Aerosol Route}

To determine the MLD of WEEV by the aerosol route, mice were exposed to a six $\log _{10}$ dose range of virus and monitored for 14 days post-challenge. The mean calculated, presented challenge dose ranged from $1.4 \times 10^{3}-0 \mathrm{pfu} /$ mouse, in direct correlation with the titre of input virus in the Collison (Table 1). The limit of detection in the plaque assay of Impinger samples is $2 \mathrm{pfu} / \mathrm{mL}$, yielding $0.3 \mathrm{pfu} / \mathrm{mouse}$ calculated presented dose. It is possible therefore, that virus was present in output aerosol samples but in a quantity below the limit of detection.

Table 1. Calculated presented exposure dose of WEEV (Fleming) to groups of Balb/c mice, with corresponding survival and clinical features. Each exposure run lasts for $10 \mathrm{~min}$ and utilizes a fresh preparation of virus $(10 \mathrm{~mL})$.

\begin{tabular}{|c|c|c|c|c|c|c|c|c|}
\hline $\begin{array}{l}\text { Exposure } \\
\text { Run } \\
\text { WEEV }\end{array}$ & $\begin{array}{c}\text { Input } \\
\text { Collison } \\
(\mathrm{pfu} / \mathrm{mL})\end{array}$ & $\begin{array}{l}\text { Output } \\
\text { Impinger } \\
(\mathrm{pfu} / \mathrm{mL})\end{array}$ & $\begin{array}{c}\text { Calc. Presented } \\
\text { Dose } \\
\text { (pfu/Mouse) }\end{array}$ & $\begin{array}{c}\text { Survival } \\
(\%)\end{array}$ & $\begin{array}{c}\text { Mean Time } \\
\text { to Death } \\
\text { (days) }\end{array}$ & $\begin{array}{c}\text { Max. Mean } \\
\text { Weight Loss } \\
(\%)^{a, b}\end{array}$ & $\begin{array}{c}\text { Max. Mean } \\
\text { Clinical } \\
\text { Score }^{a, b}\end{array}$ & 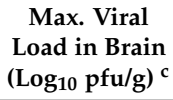 \\
\hline 1 & 0.0 & 0.0 & MOCK & $8 / 8(100)$ & - & $1.2, \mathrm{n} / \mathrm{a}$ & $0.0, \mathrm{n} / \mathrm{a}$ & - \\
\hline 2 & $1.3 \times 10^{2}$ & 0.0 & 0.0 & $8 / 8(100)$ & - & $3.0, \mathrm{n} / \mathrm{a}$ & $0.0, \mathrm{n} / \mathrm{a}$ & - \\
\hline 3 & $7.0 \times 10^{2}$ & 0.0 & 0.0 & $8 / 8(100)$ & - & $0.4, \mathrm{n} / \mathrm{a}$ & $0.0, \mathrm{n} / \mathrm{a}$ & - \\
\hline 4 & $1.9 \times 10^{4}$ & $2.2 \times 10^{1}$ & 4.0 & $7 / 8(88)$ & 5.0 & $1.3,13.7$ & $1.1,9.0$ & $9.9(n=1)$ \\
\hline 5 & $2.7 \times 10^{5}$ & $8.7 \times 10^{1}$ & $1.4 \times 10^{1}$ & $4 / 8(50)$ & 4.5 & $5.8,18.3$ & $3.7,8.7$ & $9.4(n=1)$ \\
\hline 6 & $3.1 \times 10^{6}$ & $1.0 \times 10^{3}$ & $1.7 \times 10^{2}$ & $0 / 8(0)$ & 4.5 & $17.3,17.3$ & $9.4,9.4$ & $10.1(n=4)$ \\
\hline 7 & $1.8 \times 10^{7}$ & $8.4 \times 10^{3}$ & $1.4 \times 10^{3}$ & $0 / 8(0)$ & 4.6 & $21.5,21.5$ & $8.9,8.9$ & $10.0(n=3)$ \\
\hline
\end{tabular}

${ }^{a}$ Values obtained as a mean of all mice in the group regardless of condition. ${ }^{\mathrm{b}}$ Values obtained as a mean of mice observed to have observable or pronounced clinical signs. ${ }^{\mathrm{C}}$ Values obtained from brains excised on the day mice succumbed to disease (i.e., day $4-5$ post-challenge); $8 \times 10^{9}, 2.8 \times 10^{9}, 1.2 \times 10^{10}, 9.2 \times 10^{9} \mathrm{pfu} / \mathrm{g}$ respectively.

A dose response in terms of survival was observed in mice following aerosol challenge, where an input virus challenge dose of $\geq 3.1 \times 10^{6} \mathrm{pfu} / \mathrm{mL}$ resulted in $0 \%$ survival, and $\leq 7 \times 10^{2} \mathrm{pfu} / \mathrm{mL}$ resulted in $100 \%$ survival. As mortality rates increased, weight loss and clinical scores also increased (Table 1, Figure 2). Such substantial weight loss in the high challenge doses within only 4.5 days reflected the aggressive nature of this disease in mice when exposed by the aerosol route. The mean time to death did not differ, ranging from 4.5 to 5.0 days regardless of presented challenge dose. Any mice that succumbed to lethal disease was allocated the maximum score observed (10) at the time-point that it was discovered. The maximum viral load observed in the brains of representative mice that 
succumbed to disease was also determined, demonstrating consistently high viral titres regardless of challenge dose. The lungs, spleen and livers of the same animals were also assessed. Moderate viral titres were detected in the lung, regardless of challenge dose $\left(1.7 \times 10^{2}-1.8 \times 10^{3} \mathrm{pfu} / \mathrm{g}\right)$. Virus was not detected in spleen samples with the exception of one mouse $\left(1.0 \times 10^{3} \mathrm{pfu} / \mathrm{g}\right)$ exposed to an input virus challenge dose of $3.1 \times 10^{6} \mathrm{pfu} / \mathrm{mL}$. No detectable virus was found in any liver samples tested.

Clinical signs of infection were acute and severe, particularly in the groups challenged with the highest doses of virus. Of the 48 mice exposed to WEEV Fleming, 14.6\% (7/48) succumbed to lethal disease, and $29.2 \%(14 / 48)$ were culled on welfare grounds. The frequency of observations increased to three times a day at the onset of clinical signs ( 3 days post-challenge), providing further opportunity to observe clinical signs of disease, and more importantly to reduce animal suffering. Clinical signs were most pronounced in mice that were exposed to the highest titre of virus, with observable altered behaviours; piloerection, hunched posture, eye closure (unable to open eye(s), absence of any exudate), shallow respiration, mobility issues, and seizures/tremors. Tremors/seizures were observed in 6/8 mice that were exposed to the highest titre of virus, as well as a single mouse in each of the groups exposed to doses of $1.7 \times 10^{2}$ and $4 \mathrm{pfu} /$ mouse, rapidly followed by lethal disease or a requirement to cull (within 12-24 h). Observed altered behaviour included spinning, fixed gaze, obsessive grooming behaviour, pronounced reduction in co-ordinated motor control and, occasionally, twitching. Typically, mice were free of clinical signs before abruptly presenting with multiple observable and pronounced clinical signs. Indeed, the presentation of any clinical sign resulted in a cull on welfare grounds or lethality within $24 \mathrm{~h}$ of first presentation. Commonalities between mice that presented with lethal disease revealed that a positive score for both mobility and altered behaviour, or one of these signs in combination with a positive score for altered respiration (with or without other signs), was a strong indicator of poor outcome at the next scheduled check. Mice exposed to $\leq 4 \mathrm{pfu} /$ mouse did not present with any clinical signs and maintained a typical weight profile (with the exception of a single animal exposed to $4 \mathrm{pfu} /$ mouse $\left(1.9 \times 10^{4} \mathrm{pfu} / \mathrm{mL}\right.$ input virus)). Mock challenged mice were also free of clinical signs and no ill-effects were detected as a result of being placed in the exposure apparatus and challenged with challenge media (CM) alone (no virus).

Calculation of the MLD using the formula of Reed and Muench yielded an MLD for WEEV Fleming of $11 \mathrm{pfu} /$ mouse presented dose, when challenged by the aerosol route.

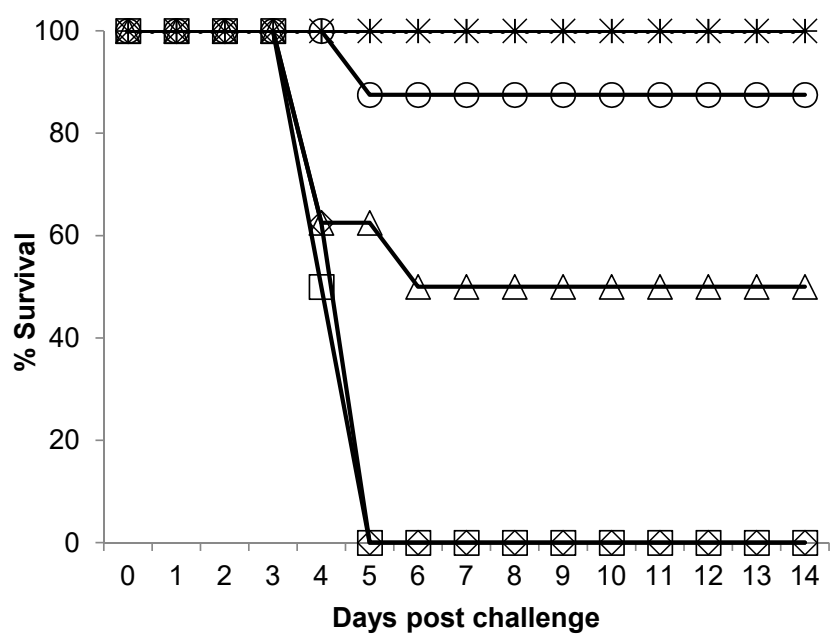

(A)

Figure 2. Cont. 


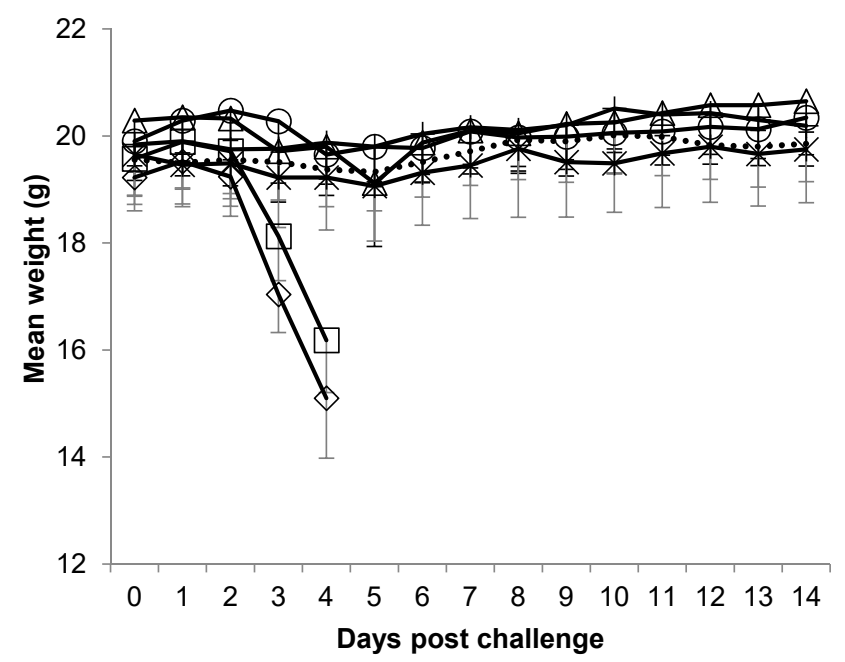

(B)

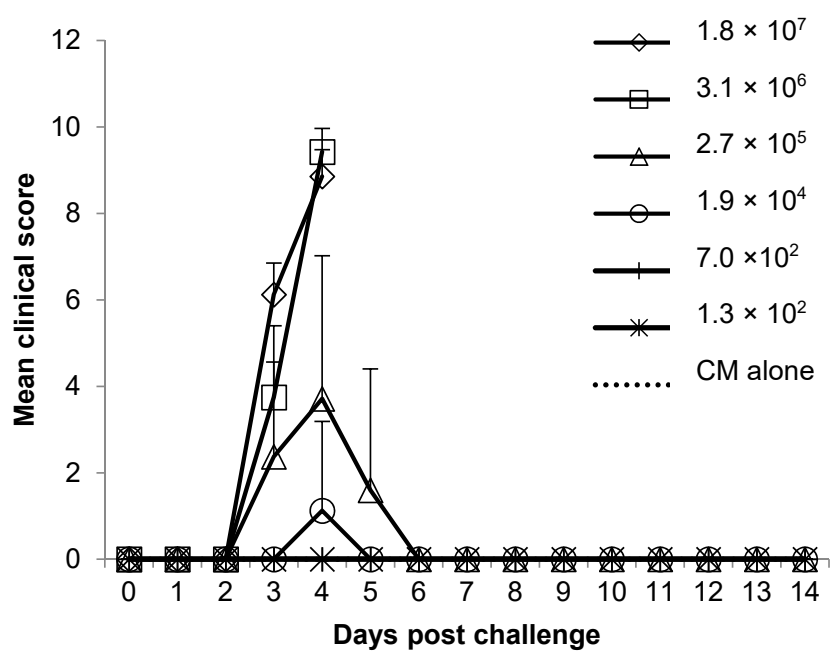

(C)

Figure 2. Key clinical outcomes in Balb/c mice exposed to a dose range of WEEV Fleming, or media control (challenge media, CM), by the aerosol route. Percentage survival (A) mean weight profile of challenge groups (B), mean clinical scores of challenge groups (C). Legend refers to input virus titre. Data points are inclusive of animals that were free of clinical signs. Error bars indicate $95 \%$ confidence interval, $n=8$.

\subsection{Pathogenesis of Western Equine Encephalitis Virus Fleming by the Aerosol Route}

The pathogenesis of WEEV infection by the aerosol route was assessed by challenging mice to a mean calculated presented dose of $\sim 10$ MLD (6.5-14.7 MLD) and sacrificing at scheduled time-points post-challenge. Blood and tissues were taken for virus enumeration, and subsets of mice were culled and fixed whole in 10\% NBF for histopathological examination. Of the 60 animals challenged with WEEV, 5 succumbed to lethal disease, 19 were culled on welfare grounds, and the remainder were culled to meet a scheduled time-point for sampling. The onset of clinical signs was observed 4 days post-challenge in the majority of mice, with three animals exhibiting mild clinical signs at 3 days post-challenge. The distribution of WEEV appeared to be generally limited to the lungs and brain, appearing first in the brain 3 days post-challenge with a mean titre of $8.12 \log _{10} \mathrm{pfu} / \mathrm{g}$, rising to 8.99 and $8.94 \log _{10} \mathrm{pfu} / \mathrm{g}$ on days 4 and 5 post-challenge. Positive lung samples were not seen until 4 days 
post-challenge, achieving 3.67 and $2.05 \log _{10} \mathrm{pfu} / \mathrm{g}$ on days 4 and 5 respectively. Detection of virus in the brain coincided with overt clinical signs of disease, with the exception of a single mouse culled at 3 days post-challenge to meet a scheduled time-point, which was free of clinical signs but positive for WEEV in the brain $\left(7.24 \log _{10} \mathrm{pfu} / \mathrm{g}\right)$. WEEV was not detected in any of the spleen samples tested, nor was viraemia observed (Figure 3). It is possible however, that virus was present in the blood and spleen either in quantities below the limit of detection or at times not examined in this study. As described previously, mice typically were free of clinical signs before abruptly presenting with observable and pronounced clinical signs. Five individual mice, which exhibited a small number of observable signs (not pronounced), had succumbed to lethal disease at the next scheduled check (days 4 and 5 post-challenge). Mice sacrificed on or after day 7 post-challenge were negative for viable WEEV in all tissue types tested. Mice that survived aerosol challenge remained free of clinical signs for the duration of the study (14 days post-challenge).

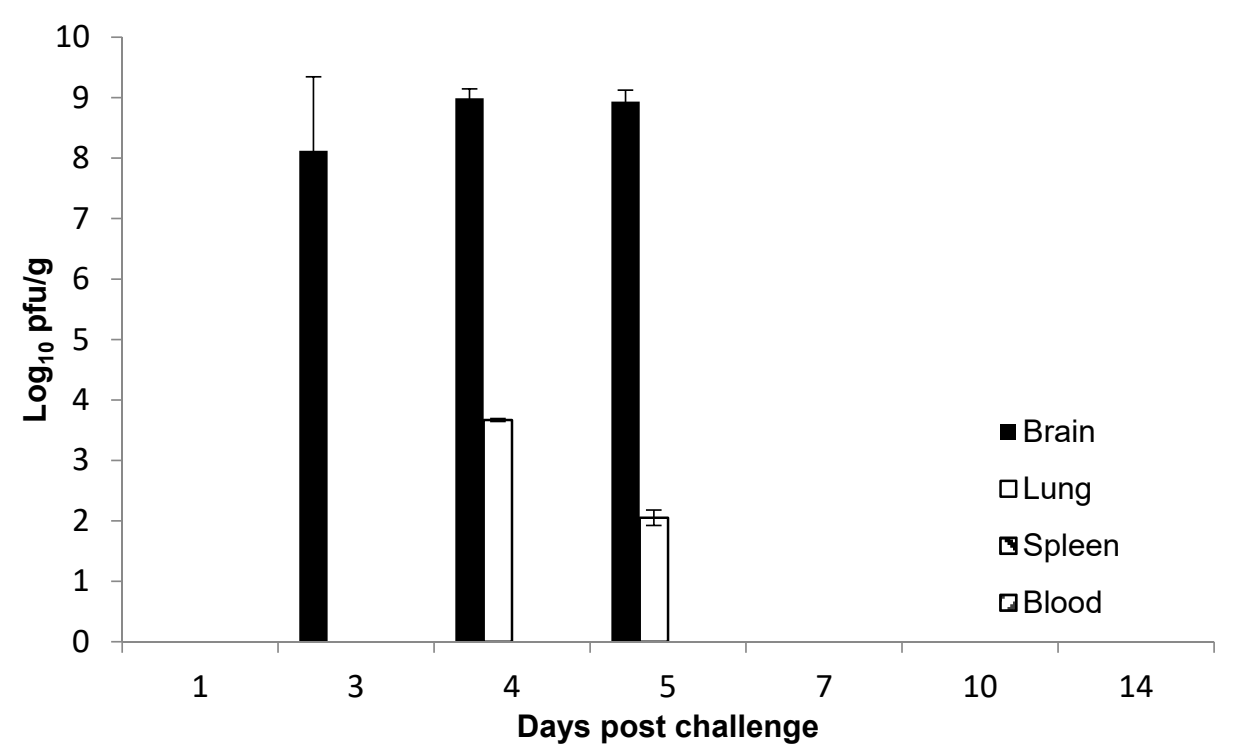

Figure 3. Mean viral load of WEEV Fleming in Balb/c mice exposed to $\sim 10 \times$ median lethal dose (MLD) by the aerosol route. Virus was not detected in spleen or blood samples at the time-points represented. Error bars represent 95\% confidence interval, $n=3-11$.

No significant histopathological findings were observed in any of the CM only (no virus) challenged animals for all tissue types examined and WEEV challenged animals were all compared to this control group (Figure 4). Specific demonstration of WEEV antigen by immuno-histochemistry (IHC) was observed as brown cytoplasmic granules in neuronal bodies and processes. Virus specific labelling of non-neuronal tissues was not possible due to excessive non-specific labelling and background staining from cellular nuclei and epithelial cell cytoplasm.

All three animals challenged with WEEV and culled one day post-challenge for histological examination were free of clinical signs and had typical weight profiles (mean weight gain of $0.8 \%$ ). There were no noteworthy changes observed in any of these animals, although the olfactory epithelium of a single mouse was observed to have a small number of distended cells in the epithelial layer with clear to eosinophilic vacuolated cytoplasm, as well as an increase of scattered pyknotic and karyorrhectic debris. WEEV viral antigen was not detected in any of the encephalic structures.

At three days post-challenge, all animals remained free of clinical signs with typical weight profiles (mean weight gain of 2.7\%), although focal lesions consistent with viral encephalitis were found in the piriform cortex of one out of three animals, with the presence of perivascular cuffing, mild focal gliosis, and pyknotic and karyorrhectic debris in some of the surrounding neurons (Figure 4). Non-specific changes observed (in the same animal), were an increase in the presence 
of tingible body macrophages in lymphoid tissues. In another of the three animals culled at this time-point, there were prominent lymphocytes attached to the endothelium of high endothelial venules in the mandibular lymph node. Two out of three animals were extensively positive for WEEV antigen in the brain (not subject to decalcification) and olfactory bulb (decalcified and processed with the nasal cavity and cranium), although only one of these two animals was observed to have lesions in the brain. In both cases, the extension of viral antigen was wider and more caudal than the presence of histological lesions observed in a single animal. Viral antigen extended caudally throughout all encephalic areas to the brainstem, although it was not present in the cerebellum. The immune-labelling was more abundant in rostroventral areas and there was also a bilateral distribution of virus in the brain, with a degree of variability between both sides.

By four days post-challenge there were significant nervous clinical signs in all mice selected for pathological examination, three of which had succumbed to lethal disease, and two of which were culled on welfare grounds. In the animals that had succumbed to lethal disease, a severe meningoencephalitis with acute cell death and degenerative changes in neurons and leukocytes in the encephalon, with marked rarefaction and oedema of the neuroparenchyma was observed (Figure 4). Lesions were bilateral, with individual variability, with one side of the brain more severely affected. Lesions were more severe in rostroventral regions of the encephalon, especially in the olfactory bulbs and the piriform cortex. All layers of the cortical neurons were affected, with mild expansion of perivascular spaces and rare perivascular cuffs containing only pyknotic/karyorrhectic debris, although areas with distinct focal gliosis or glial nodules were absent. The two animals culled on welfare grounds also had bilateral lesions in the cortex and caudate putamen of the encephalon, with marked bilateral differences (rostroventral cortex, primary piriform cortex). Morphological changes in these two animals were similar to those in animals that had succumbed to infection at this time-point, albeit less extensive, with mild leptomeningeal histiocytic infiltration. In the olfactory epithelium, attenuation or thinning of the layers of supporting cells and olfactory neurons was noted in most animals 4 days post-challenge, associated in many occasions with non-specific changes as cellular vacuolation and frequently an increase in cell debris. Morphological changes on lymphoid tissue were inconsistent between animals and similar to those observed at three days post-challenge. Interestingly, a single mouse was positive for viral antigen by IHC in the retina, specifically in the neurons of the ganglion, plexiform, and internal nuclear layers. However, non-specific intra-nuclear labelling of the photoreceptors was also evident, obscuring any specific labelling in the external nuclear layer (Figure 4).

Two out of three animals processed five days post-challenge had succumbed to infection (mean weight loss of $1.9 \mathrm{~g}$ ), and had comparable histopathology findings in the encephalon, olfactory bulb, olfactory epithelium, and thymus, as the animals processed from day post-challenge. A third animal was within normal limits for all tissue types tested. This animal was free of clinical signs and had a typical weight profile (mean weight gain of $1.0 \mathrm{~g}$ ). All other remaining animals processed $\geq 7$ days post-challenge were also within normal limits for all tissue types tested. 


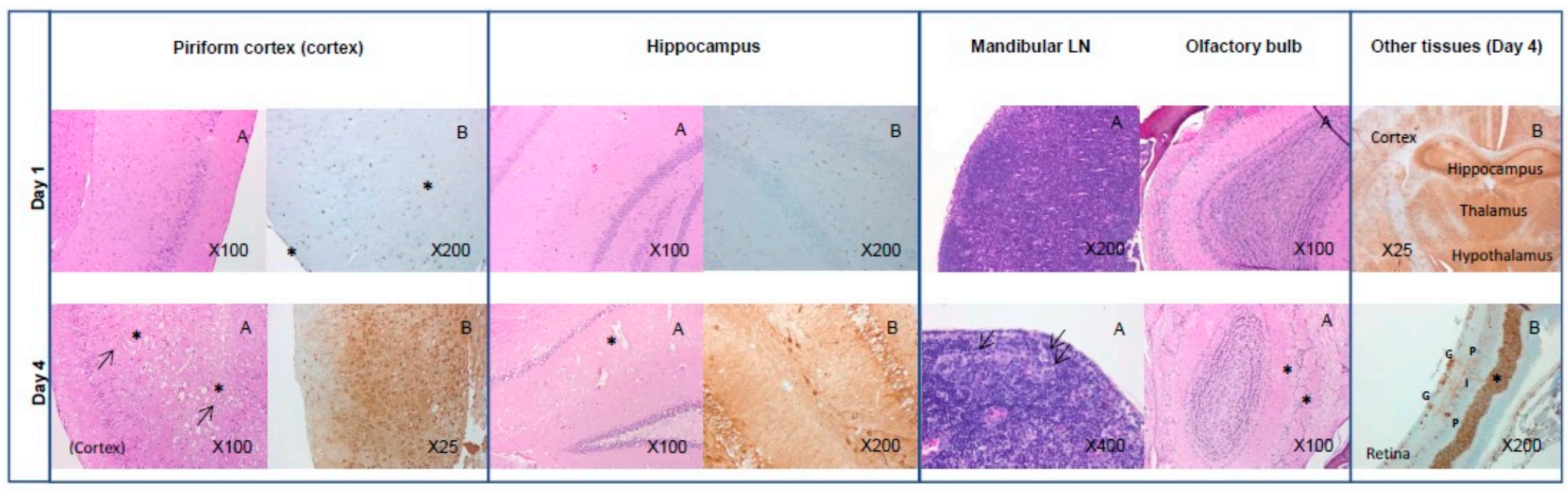

Figure 4. Histopathology (A) and immuno-histochemistry (IHC) (B) images from Balb/c mice exposed to $\sim 10 \times$ MLD WEEV Fleming by the aerosol route. Mice were sacrificed at intervals post challenge to meet a sampling time-point, or were culled on welfare grounds. Representative neuronal tissues from infected (day four post-challenge) and challenge media (CM) alone (no virus, day 1 post-challenge) exposed mice demonstrate clear WEEV-induced pathology. CM alone (no virus) tissue types were all within normal limits, with well-defined neuronal layers and distinct nuclei. The piriform cortex is within normal limits with minor non-specific labelling in the nuclei of endothelial cells in blood vessels of the cortex and meninges $\left(^{*}\right)$ One day post-challenge. By four days post-challenge there is rarefaction of the grey matter $(*)$ with shrunken pyknotic nuclei and vacuolation of neurons (marked with arrows). IHC staining shows the diffuse spread of virus in the piriform cortex. In the hippocampus severe and extensive bilateral lesions are evident four days post-challenge. There is rarefaction of the neuroparenchyma ${ }^{*}$ ) with neuronal degeneration and necrosis, as well as neuropil vacuolation. There are also shrunken, hyperchromatic nuclei and neuronal bodies with angular shapes, and pyknotic and karyorrhectic debris. In the mandibular lymph node (LN) four days post-challenge there is an increase in the number of macrophages containing pyknotic and karyorrhectic debris (tingible body macrophages), marked with arrows. In the olfactory bulb there is a clear loss of neurons, with disruption of normal structure (*) four days post-challenge. Nuclei are much smaller and hyperchromatic, with no clear cell limits. The low magnification image of the cortex, hippocampus, thalamus, and hypothalamus demonstrates the diffuse presence of WEEV at four days post-challenge. The retina is positive for WEEV in the neurons of the ganglion layer (G), plexiform layers (P) and internal nuclear layer (I), although there is non-specific intranuclear labelling in the external nuclear layer ( ${ }^{*}$ photoreceptors) (sample obtained four days post-challenge). 


\section{Discussion}

Aerosol infection is the likely route of exposure to WEEV in a biowarfare scenario, and one way in which laboratory personnel may be accidentally exposed. It is therefore critical to understand the susceptibility, lethality and pathogenesis of infection when exposed by this route. In this study, aerosol exposure to WEEV Fleming was lethal in adult female Balb/c mice. The disease course was acute (with mice succumbing abruptly $4-5$ days post-challenge), with severe clinical signs, rapid neuroinvasion and $100 \%$ mortality observed when challenged with $\geq 1.7 \times 10^{2}$ pfu presented dose. This compares with another study [18] using intranasal infection with a high and low virulence strains of WEEV, including Fleming. The mean time to death for high virulence strains was 5-6 days post-challenge, as opposed to $4-5$ days by the aerosol route seen here. This is also in-line with a related encephalitic alphavirus, EEEV, where virus was first found in the brain at $6 \mathrm{~h}$ after aerosol challenge, and $24 \mathrm{~h}$ after intranasal challenge [21].

The MLD in this model of WEEV Fleming was calculated to be $11 \mathrm{pfu} /$ mouse presented dose, by the aerosol route. The MLD for WEEV Fleming has not previously been determined for rodents infected by the aerosol route, although intraperitoneal, subcutaneous, and intra-nasal challenges of C57/BL6 mice with the CBA 87 strain, suggest that these routes require at least a 10-fold greater challenge dose to cause lethality [15]. Luciferase-expressing WEEV has previously been used to track infection in CD-1 outbred mice exposed by the intra-nasal route, revealing that neuroinvasion occurs primarily via cranial nerves, chiefly in the olfactory tract [16]. This may explain the rapid neuroinvasion of WEEV into the brains of mice exposed to $10 \times$ MLD in this study, where viable virus was detected at near-peak levels as early as three days after aerosol challenge (Figure 3). The 3-jet collision nebulizer generates particles in the range of 1-3 microns, which is in the respirable range for deep lung inhalation [22-24]. Our data suggest that despite the particle size being suited to deposition in the deep lung, the virus preferentially utilizes the olfactory processes as a route to the brain. If so, the disparity between the different sides of the brain with respect to number of lesions may be the result of uneven uptake of virus by the olfactory epithelium, and therefore uneven distribution of virus between the left and right olfactory bulbs. However, we do not have quantitative data to support this theory.

Phillips et al. summarized bioluminescent WEEV pathogenesis as occurring in three phases; (1) extraneural viral lesions, within $24 \mathrm{~h}$ post-challenge (2) neuroinvasion, within $24-48 \mathrm{~h}$ post-challenge, and (3) central nervous system (CNS) dissemination, 48-72 $\mathrm{h}$ post-challenge [25]. IHC analysis of both WEEV antigen and luciferase in their study demonstrated that infection was almost entirely limited to neurons and that dissemination was probably via neuronal connectivity. Our viral load and dissemination data, as well as histopathological findings, were in general agreement with this published data from intranasal challenge, although the timings of the phases were delayed in comparison. The altered kinetics may be due to differences in challenge dose, challenge route, strain of virus, and/or host factors.

In Balb/c mice challenged with WEEV Fleming by the aerosol route, extraneural lesions were detected three days post-challenge, although as samples were not taken two days post-challenge, it is possible that lesions appeared earlier than this. There was clear evidence of neuroinvasion at three days post-challenge, as demonstrated by the viral load and virus detection by IHC, although lesions were very limited. This appears to be representative of the early clinical phase of the disease, and could possibly offer a window of opportunity for the administration of any medical countermeasure. By day four post-challenge, focused lesions were observed in the encephalon of mice culled on welfare grounds, and extensive bilateral lesions were found throughout the encephalon in mice that had succumbed to lethal disease. Of interest was the detection of WEEV antigen in the retina of a single mouse culled four days post-challenge; a finding that has not been reported previously, and may in-part be why these animals were observed to have eye issues. By day five post-challenge, extensive bilateral lesions in the encephalon were also present in animals that had succumbed to lethal disease. By design, a number of mice survived the aerosol challenge and they were all free of clinical signs 
and free of noteworthy pathological findings at the point at which they were sacrificed ( $\geq 7$ days post-challenge). This suggests that adult Balb/c mice were either not exposed to sufficient virus to cause infection, or were able to mount an effective immune response to challenge with $10 \times$ MLD of WEEV by the aerosol route. The former is unlikely, as cage-mates exposed concurrently to the same aerosol challenge exhibited pronounced clinical signs of disease, and succumbed to infection. The latter, therefore, would be the most probable explanation, although the immune response to infection was not characterized in these studies as it was beyond the scope of the program of work.

In a Sindbis virus (SINV) model of alphavirus-induced encephalitis, Metcalf et al. [26] IFN $\gamma$ demonstrated that viral clearance from intra-cerebral inoculation in mice occurred in three phases: clearance of infectious virus (from three days post-challenge), clearance of viral RNA (from eight days post-challenge), and retention of low levels of viral RNA ( $>60$ days post-challenge). The adaptive immune response was initiated in the draining cervical lymph nodes, with $\mathrm{CD} 8^{+} \mathrm{T}$ cells being the first to enter the brain, rapidly followed by other immune cells. The viral clearance phase correlated with SINV-specific immunoglobulin (Ig)M secretion, and viral RNA clearance correlated with an abundance of inflammatory cells, SINV-specific IgG, and memory B cell production. Non-cytolytic markers of viral clearance included interferon (IFN) $\gamma$ (likely to be produced by local CD8 ${ }^{+} \mathrm{T}$ cells) and IgG, both of which are also important in other CNS virus infections [27-30], and may account for the absence of histopathology findings in surviving mice in this study. It has been shown [20] that passive transfer of serum from glycoprotein E1-immunized mice to naïve mice, conferred protection against WEEV challenge. This and other research identified virus-specific antibody as being an important component in recovery from a lethal challenge of WEEV [31], although such rapid production in naïve mice post-challenge was unlikely. [32] examined the immunological profile of Balb/c mice protected from aerosol VEEV challenge following vaccination with a live attenuated vaccine, which demonstrated protection despite the absence of detectable levels of virus-specific IgG or IgA antibody.

In this study, we have expanded a clinical scoring system previously described for the low-virulence WEEV 71V-1658 intra-nasal challenge model [33], for use with high-virulence WEEV Fleming strain, in aerosol challenges in mice. The weight loss observed in infected mice was a good indicator, but not a good predictor of outcome as the disease course was acute. Any mouse observed to have pronounced mobility issues (unable to reach food and water) was culled on welfare grounds in order to comply with UK Home Office Licensing requirements. Further to this, mice found to have observable mobility issues and altered behaviour, or one of these signs in combination with observable respiratory issues, rapidly succumbed to infection (within 12-24 h). This combination of clinical signs may be a useful way to determine a humane end-point. Pronounced altered behaviour (spinning, obsessive grooming, lack of coordinated motor control) coincided with high viral titres of WEEV in the brain at three days post-challenge. It seems likely that viral colonisation of the brain was the cause of this behaviour, although this could be tissue-dependent and/or viral load-dependent within the brain, as one mouse positive for WEEV in the brain three days post-challenge was free of all clinical signs, including altered behaviours. This particular animal had a titre of $7.24 \log _{10} \mathrm{pfu} / \mathrm{g}$, compared to $9.01 \log _{10} \mathrm{pfu} / \mathrm{g}$ in an animal sacrificed at the same time but that displayed signs of altered behaviour (and other clinical signs). In addition, in mice that succumbed to disease, as opposed to being sacrificed for time points, the viral load in the brain appeared to be independent of the challenge dose (Table 1). This suggests that severe clinical signs are associated with a high level of virus replication in the brain, and that a major component of recovery may be mechanisms that limit viral replication in brain tissue. If this is the case, the critical difference between low and high dose challenges is a greater likelihood of achieving a high viral load in the brain in high dose challenges, and the important issue for development of medical countermeasures may be to limit virus replication in the brain, rather than prevent neuroinvasion completely.

The above analysis is supported by the lack of viable WEEV in blood, the majority of spleens, and all but a single liver sample at the time-points chosen. This suggests that inhaled virus can cause lethal disease with little apparent replication in peripheral tissues. Ref. [15] made the same observation 
in intra-nasally infected WEEV CBA 87 mice, where WEEV was not detected in the spleen, liver, lung, kidney, or heart at the time-points studied. In contrast, mice infected by the sub-cutaneous or intra-peritoneal route with WEEV CBA 87 were positive in all extraneural tissues tested. In humans, WEEV is rarely isolated from blood or cerebro-spinal fluid when patients present with overt clinical signs, although virus has been isolated from brain tissue in biopsy or at autopsy [2].

The Balb/c mouse displays overt clinical signs of WEEV disease that reproduce the most severe clinical symptoms observed in humans. In humans, clinical features may include abrupt onset of fever, headache, nausea, vomiting, anorexia, viremia, and general malaise. A minority of those infected may also go on to have an altered mental state (confusion, lack of co-ordination), seizures, and encephalitis, leading to coma and possibly death. In the present mouse model of aerosol induced infection, the non-specific clinical features present abruptly as a combination of clinical signs; ruffled fur, hunched posture, a change in respiratory rate, weight loss, and one or both eyes closed. This very rapidly leads to altered behaviour, mobility issues and in some cases, tremors/seizures, all of which were lethal in this model of disease. An aerosol challenge of WEEV Fleming by the aerosol route provided a set of clinical signs that were consistent with those reported in human disease. The mortality rate however was higher in mice than in naturally occurring epizootic episodes, and this was likely, among other factors, to be attributed to the route of infection, and the relative susceptibility of the Balb/c mouse to WEEV. Human cases of aerosol infection are rare with limited detail surrounding accidental exposures of laboratory personnel, although a single report by [7] registers mortality as being $40 \%(2 / 5)$.

This report has detailed the susceptibility of adult Balb/c mice to WEEV Fleming by the aerosol route and the associated presented MLD. The pathogenesis of disease has also been described, particularly detailing viral load and distribution, histopathology within target neuronal tissues, and a provisional clinical scoring system for use in assessing animal condition and to determine a humane end-point. Reproduction of the most severe clinical features of human WEEV disease in mice should allow researchers to robustly assess antiviral therapies or vaccines for this Hazard Group 3 (HG 3) bio-threat agent. Understanding the pathogenesis of disease in an animal model is critical to being able to target key tissues and key intervention times in disease progression, and to further understand the full effects of any clinical interventions. This in vivo mouse model may be a useful tool in assessing the utility of putative medical countermeasure against WEEV, both prophylactically and therapeutically, and provide key data pertaining to the efficacy of any medical countermeasures against a rapidly neuroinvasive aerosol challenge. Clinical features of disease and viral load analysis will be key parameters in this acute model, and a program of work is required to elucidate the immunological profile in Balb/c mice infected with WEEV Fleming.

\section{Materials and Methods}

\subsection{Cells and Virus}

WEEV strain Fleming was kindly supplied by Les P. Nagata (Defense Research and Development Canada). The preparation of virulent stocks in suckling mice has been described previously [34], and titre determined by standard plaque assay methods utilising a carboxymethyl cellulose overlay. Briefly, suckling mouse pups were inoculated intra-cranially with WEEV Fleming and were moribund within $24 \mathrm{~h}$, at which point they were culled with an overdose of sodium pentobarbital, and stored at $-70^{\circ} \mathrm{C}$. Virus was harvested by aspirating the brain through the dorsal cranium with a large-bore syringe needle and expelled into Leibovitz L-15 media supplemented with $2 \%(v / v)$ foetal calf serum (Gibco, ThermoFisher Scientific, Loughborough, UK). This preparation was homogenised by passing through a $70 \mu \mathrm{m}$ nylon cell strainer, and clarified at 10,000 rpm for $10 \mathrm{~min}$ in a SW28 rotor (Beckman Coulter, High Mycombe, UK). The supernatant was titrated and stored at $-80{ }^{\circ} \mathrm{C}$ until required. All work with WEEV was carried out under UK Advisory Committee on Dangerous Pathogens Level 3 (BSL3) containment. Fleming is a pathogenic, neurotropic strain of WEEV from 
a human isolate obtained during a Californian outbreak, with $98.6 \%$ nucleotide identity to the closely related, and commonly studied California strain of WEEV (horse isolate) [18]. When compared to one another in an intranasal model of infection in mice, both Fleming and California were highly comparable in disease outcome and grouped along with the McMillan strain, as pathotype A [18].

Vero cells were obtained from the European Collection of Animal Cell Cultures (ECACC, Salisbury, UK) and propagated in Dulbecco's minimal essential medium with $10 \%(v / v)$ foetal calf serum, $2 \mathrm{mM}$ L-glutamine, $50 \mathrm{IU} / \mathrm{mL}$ penicillin and $50 \mu \mathrm{g} / \mathrm{mL}$ streptomycin, at $37^{\circ} \mathrm{C}$, in a $5 \% \mathrm{CO}_{2}$ humidified atmosphere. For virus culture, Vero cells were maintained in Leibovitz L-15 media supplemented with $2 \%(v / v)$ foetal calf serum, $2 \mathrm{mM}$ L-glutamine, $50 \mathrm{IU} / \mathrm{mL}$ penicillin and $50 \mu \mathrm{g} / \mathrm{mL}$ streptomycin (Maintenance Media; MM), at $37^{\circ} \mathrm{C}$. Aerosol challenge preparations were made in L-15 media supplemented with $2 \mathrm{mM}$ L-glutamine only (Challenge Media; $\mathrm{CM}$ ). Media and supplements came from two sources; Sigma Aldrich, Poole, UK and Gibco, ThermoFisher Scientific, Loughborough, UK.

Plaque assays were routinely performed in a 24-well plate format with duplicate wells for each dilution step, and virus inoculum applied to wells in $100 \mu \mathrm{L} /$ well. The limit of detection in this assay is $10 \mathrm{pfu} / \mathrm{mL}$ of original sample. The exceptions were aerosol samples collected in Impingers (output virus), which were performed in a 6-well plate format with duplicate wells for each dilution step, and virus inoculum applied to wells in $500 \mu \mathrm{L} /$ well. The limit of detection for Impinger samples is $2 \mathrm{pfu} / \mathrm{mL}$.

\subsection{Aerosol Generation and Challenge}

Three experiments were conducted to assess the effect of aerosolisation on the viability and calculated presented dose of WEEV Fleming. The aerosol was generated using a 3-jet Collison nebulizer, containing $10 \mathrm{~mL}$ of virus (input virus), controlled and conditioned to $50 \%( \pm 5 \%)$ relative humidity by an AeroMP platform system (Biaera Technologies, Hagerstown, MD, USA). Aerosols were generated for a total of $9 \mathrm{~min}$, with aerosol sampling achieved using an all-glass impinger (AGI-30; Ace Glass, Vineland, NJ, USA) containing $10 \mathrm{~mL}$ phosphate buffered saline (output virus). A total of three samples were taken during aerosolisation for $1 \mathrm{~min}$ each, at a flow rate of $12 \mathrm{~L} / \mathrm{min}$. All virus samples were kept on ice until used or titrated.

After characterising virus output from aerosols, the aerosol challenge for in vivo experiments was generated as described above; mice were physically restrained in holding tubes and nose-only exposed to the aerosol for $10 \mathrm{~min}$. A single sample of each aerosol exposure was taken using an AGI-30 as described. A maximum of 20 mice were challenged in any single aerosol exposure, with fresh virus preparations used for each exposure. The mean calculated, presented challenge dose was determined using the viral titres obtained from the Impingers (output virus), and Guyton's formula for the respiratory volumes of laboratory animals [35].

\subsection{Mouse Studies}

Female, Balb/c mice (aged 7-9 weeks), with micro-chip; (Charles River Laboratories, Margate, UK) weighing between 18-20 g were appropriately housed with access to food and water ad libitum in a rigid-walled BSL3 containment isolator. All studies were performed in accordance with the UK Scientific Procedures (Animals) Act 1986 and the UK Codes of Practice for the Housing and Care of Animals Used in Scientific Procedures 1989 (as well the Animal Care and Use Review Office, Fort Detrick, MD, USA ). Prior to commencing the study, mice were acclimatised in the BSL3 isolator for a minimum of five days and were weighed prior to aerosol challenge. Post-challenge, a clinical scoring system was employed based on our previous experience of exposing Balb/c mice to the closely related Venezuelan equine encephalitis virus, by the aerosol route [36]. Scores were assigned on a truncated scale of 0 (absent), 1 (observable), and 2 (pronounced), and were based on observations of coat condition, hunched posture, respiratory state, eye condition, tremors, changes in behaviour, ability to move, and paralysis (Table 2). After challenge, all animals were weighed daily and observed a minimum of twice daily for clinical signs of infection by an independent observer who 
was unaware of group allocation. As clinical scoring is a subjective measure, it is important to ensure the use of independent personnel to conduct the scoring and monitoring where possible. Personnel must also have sufficient experience in understanding the normal behaviour and condition of a Balb/c mouse, to then be able to make consistent judgements about diseased animals. Any mouse observed to be paralysed or to have pronounced mobility issues (unable to reach food and water) was culled on welfare grounds. At the onset of severe clinical signs the frequency of observations was increased, in accordance with UK Home Office requirements. All culls were performed using a UK Schedule 1 method (cervical dislocation followed by confirmation of cessation of heart beat).

Table 2. Clinical scoring system employed to monitor the clinical course of WEEV disease in adult Balb/c once exposed to an aerosol challenge of WEEV Fleming. Animals scoring 2 for mobility or paralysis were culled immediately on welfare grounds.

\begin{tabular}{|c|c|c|c|c|c|c|c|c|}
\hline Score & Coat & Posture & Respiration & $\begin{array}{c}\text { Eye } \\
\text { Condition }\end{array}$ & Tremors & Behaviour & Mobility & Paralysis \\
\hline 1 & $\begin{array}{l}\text { Observable } \\
\text { ruffling }\end{array}$ & $\begin{array}{l}\text { Observable } \\
\text { hunched } \\
\text { posture }\end{array}$ & $\begin{array}{l}\text { Breathing is } \\
\text { fast/slow }\end{array}$ & $\begin{array}{l}\text { Issues with } \\
\text { one or both } \\
\text { eyes but is } \\
\text { able to open at } \\
\text { least one eye }\end{array}$ & $\begin{array}{l}\text { Observable } \\
\text { tremors or } \\
\text { shaking }\end{array}$ & $\begin{array}{l}\text { Behaviour or } \\
\text { activity is } \\
\text { fast/slow or } \\
\text { unusual }\end{array}$ & $\begin{array}{l}\text { Movement is } \\
\text { slow. May be } \\
\text { visible limb } \\
\text { issues }\end{array}$ & $\mathrm{N} / \mathrm{A}$ \\
\hline 2 & $\begin{array}{l}\text { Pronounced } \\
\text { ruffling }\end{array}$ & $\begin{array}{l}\text { Pronounced } \\
\text { hunched } \\
\text { posture }\end{array}$ & $\begin{array}{l}\text { Breathing is } \\
\text { extremely } \\
\text { laboured or } \\
\text { fast }\end{array}$ & $\begin{array}{l}\text { Issues with } \\
\text { both eyes and } \\
\text { unable to open } \\
\text { them }\end{array}$ & $\begin{array}{l}\text { Pronounced } \\
\text { tremors or } \\
\text { shaking }\end{array}$ & $\begin{array}{l}\text { Pronounced } \\
\text { altered } \\
\text { behaviour } \\
\text { such as } \\
\text { extreme } \\
\text { activity, } \\
\text { spinning }\end{array}$ & $\begin{array}{l}\text { Immobile, not } \\
\text { moving } \\
\text { despite } \\
\text { provocation. If } \\
\text { turned on } \\
\text { back is unable } \\
\text { to right itself }\end{array}$ & $\begin{array}{l}\text { Observable } \\
\text { paralysis of } \\
\text { any limbs }\end{array}$ \\
\hline
\end{tabular}

\subsection{Median Lethal Dose of Western Equine Encephalitis Virus by the Aerosol Route in Balb/c Mice}

Six groups of eight mice were challenged by the aerosol route with a dilution range of WEEV Fleming. Virus was diluted in CM to yield $5 \times 10^{7} \mathrm{pfu} / \mathrm{mL}$, and 10 -fold dilutions were prepared to $5 \times 10^{2} \mathrm{pfu} / \mathrm{mL}$ for use as input virus in the Collison nebulizer. A control group of seven mice were challenged with CM only (no virus) by the aerosol route, and placed in the first challenge run. All mice were weighed daily and scored for clinical signs of disease at least twice daily. Tissues of mice which succumbed to infection were excised to determine viral load. The MLD was calculated using the $50 \%$ end point calculation of Reed \& Muench [37] and was based on the number of surviving animals from each exposure group 14 days post-challenge.

\subsection{Pathogenesis of Western Equine Encephalitis Virus by the Aerosol Route in Balb/c Mice}

Mice were challenged with $\sim 10 \times$ MLD WEEV Fleming by the aerosol route as described above, and groups culled on successive days (1, 3, 4, 5, 7, 10, and 14 days post-challenge). At the scheduled time-points, groups were anaesthetized with gaseous halothane and exsanguinated by cardiac puncture prior to cull by cervical dislocation. Brain, lung, and spleen were separately prepared for virus enumeration by homogenisation through a $40 \mu \mathrm{m}$ cell sieve (Corning Falcon cell strainer, Fisher Scientific, Loughborough, UK) into $1 \mathrm{~mL}$ MM. Serial dilutions were prepared from homogenates in $\mathrm{MM}$ and added to duplicate cell monolayers for plaque titration in 24-well tissue culture plates under a carboxymethyl cellulose (CMC) overlay. Neat samples of blood obscure the cell monolayer in plaque titration experiments and were not assayed. Blood samples therefore have a higher limit of detection $(100 \mathrm{pfu} / \mathrm{mL})$. All plates were incubated for $3-4$ days at $37^{\circ} \mathrm{C}$ in a humidified atmosphere before fixation of monolayers with $10 \%(v / v)$ formal saline solution and staining with $0.1 \%(w / v)$ crystal violet to visualise plaques.

At least 3 whole mice per scheduled cull were terminally anaesthetized with gaseous halothane (confirmation of cull by cessation of heart beat), and prepared for immersion in 10\% neutral buffered formalin (NBF; SigmaPoole, UK) for histological analysis. Carcass preparation for immersion in NBF required full abdominal, thoracic, and cranial cavity access to ensure complete virus inactivation prior 
to removal of carcasses from high containment. A control group of 10 mice, challenged with CM only, was included and culled one day post-challenge.

Following preservation in $10 \% \mathrm{NBF}$, the following tissues were dissected from each individual carcass and routinely processed for histopathology: brain (six coronal sections as described by Hicks et al. [38], to allow examination of the olfactory bulbs, cortex, hippocampus, thalamus, hypothalamus, pons, cerebellum, and medulla), lung, heart, trachea, mediastinal structures including thymus and mediastinal lymph nodes, mandibular lymph nodes, and salivary glands. The left femur and the facial and cranial structures were subjected to a minimum of $48 \mathrm{~h}$ decalcification in Gooding and Stewart's fluid, a 1:1:18 solution of 96-100\% formic acid (VWR Chemicals, Leighton Buzzard, UK), $36 \%$ formaldehyde (VWR Chemicals) and purified water, prior to preparation of cross sections to allow the examination of the bone structures of femur, face, oral cavity and teeth, nasal cavity, nasal associated lymphoid tissues, and eyes. All samples were routinely processed and embedded in paraffin wax. $4 \mu \mathrm{m}$ thick sections were cut and either stained with haematoxylin and eosin, or used for IHC detection of viral antigen. WEEV was detected by IHC using automated protocols optimised for use on the Ventana Discovery XT staining module (Ventana Medical Systems, Tucson, AZ, USA).

Tissue sections were de-waxed prior to antigen retrieval, using a standard CC2 (Ventana Medical Systems, Tucson, AZ, USA) cell conditioning regime for rabbit anti-WEEV E2 glycoprotein (Integrated Biotherapeutics, Rockville, MD, USA) polyclonal antibody (pAb) protocol. Primary anti-WEEV pAb $(4 \mu \mathrm{g} / \mathrm{mL})$ diluted in Ventana Ab Diluent (Ventana Medical Systems) was applied for $60 \mathrm{~min}$ at room temperature. Antibody-antigen interaction was detected and amplified using anti-rabbit HRP multimer (Ventana Medical Systems) for $16 \mathrm{~min}$ and visualised using a ChromoMap DAB kit (Ventana Medical Systems). Formalin-fixed, paraffin-embedded tissue sections were counterstained in haematoxylin (Ventana Reagents, Tucson, AZ, USA) for 8 min, before being permanently mounted for interpretation. Concentration-matched $(4 \mu \mathrm{g} / \mathrm{mL})$ rabbit antibody isotype (Vector Laboratories, Peterborough, UK) controls diluted in Ventana Ab diluent were included as test controls.

Acknowledgments: This work was funded by Mapp Biopharmaceutical Inc through a Defense Threat Reduction Agency funded research program, Award number HDTRA1-14-1-0115. The grateful assistance of Mr. A. Sinclair and Dstl animal technicians, especially Mr. G. Evans is acknowledged and appreciated.

Author Contributions: A.L.P., M.S.L., D.O.U. conceived, and designed the experiments; A.L.P., L.O.B., L.S.E., C.D. and A.N. performed the experiments; A.L.P., M.S.L. and D.O.U. analyzed the data; A.N. wrote the histopathology elements of the paper; A.L.P. wrote the paper; J.E. and L.Z. funded the research.

Conflicts of Interest: The authors declare no conflicts of interest.

\section{References}

1. Weaver, S.C.; Paessler, S. Alphaviral Encephalitides. In Vaccines for Biodefense and Emerging and Neglected Disease; Barret, A.D.T., Stanberry, L.R., Eds.; Academic Press: London, UK, 2009; Chapter 21.

2. Weaver, S.C.; Powers, A.M. Alphaviruses: Equine Encephalitis and Others. In Viral Infections of Humans: Epidemiology and Control; Kaslow, R.A., Stanberry, L.R., Le Duc, J.W., Eds.; Springer: New York, NY, USA, 2014.

3. Reeves, W.C.; Huston, G.A.; Bellamy, R.E.; Scrivani, R.P. Chronic latent infections of birds with Western equine encephalomyelitis virus. Proc. Soc. Exp. Biol. Med. 1958, 97, 733-736. [CrossRef] [PubMed]

4. Hollidge, B.S.; Gonzalez-Scarano, F.; Soldan, S.S. Arboviral encephalitides: Transmission, emergence and pathogenesis. J. Neuroimmune Pharmacol. 2010, 5, 428-442. [CrossRef] [PubMed]

5. Ronca, S.E.; Dineley, K.T.; Paessler, S. Neurological sequelae resulting from encephalitic alphavirus infection. Front. Microbiol. 2016, 20, 959. [CrossRef] [PubMed]

6. Reisen, W.K.; Monath, T.P. Western equine encephalomyelitis. In The Arboviruses: Epidemiology and Ecology; Monath, T.P., Ed.; CRC Press: Boca Raton, FL, USA, 1988; Volume V, pp. 89-137.

7. Hanson, R.P.; Sulkin, S.E.; Buescher, E.L.; McD Hammon, W.; McKinney, R.W.; Work, T.H. Arbovirus infections of laboratory workers. Science 1967, 158, 1283-1286. [CrossRef] [PubMed]

8. Sidwell, R.W.; Smee, D.F. Viruses of Bunya- and Togaviridae families: Potential as bioterrorism agents and means of control. Antivir. Res. 2003, 57, 101-111. [CrossRef] 
9. National Institute of Allergy and Infectious Diseases. Available online: http://www.niaid.nih.gov/topics/ biodefenserelated/Pages/default.aspx (accessed on 10 March 2017).

10. Center for Disease Control and Prevention. Available online: www.cdc.gov/phpr/publications/2008/ appendix6.pdf (accessed on 10 March 2017).

11. Reed, D.S.; Larsen, T.; Sullivan, L.J.; Lind, C.M.; Lackemeyer, M.G.; Pratt, W.D.; Parker, M.D. Aerosol exposure to Western equine encephalitis virus causes fever and encephalitis in cynomolgus macaques. J. Infect. Dis. 2005, 192, 1173-1182. [CrossRef] [PubMed]

12. Julander, J.G.; Siddharthan, V.; Blatt, L.M.; Schafer, K.; Sidwell, R.W.; Morrey, J.D. Effect of exogenous interferon and interferon inducer on western equine encephalitis virus disease in a hamster model. Virology 2007, 360, 454-460. [CrossRef] [PubMed]

13. Aguilar, M.J. Pathological changes in brain and other target organs of infant and weanling mice after infection with non-neuroadapted Western equine encephalitis virus. Infect. Immun. 1970, 2, 533-542. [PubMed]

14. Monath, T.P.; Kemp, G.E.; Cropp, C.B.; Chandler, F.W. Necrotizing myocarditis in mice infected with Western equine encephalitis virus: Clinical, electrocardiographic, and histopathologic correlations. J. Infect. Dis. 1978, 138, 59-66. [CrossRef] [PubMed]

15. Blakely, P.K.; Delekta, P.C.; Miller, D.J.; Irani, D.N. Manipulation of host factors optimizes the pathogenesis of Western equine encephalitis virus infections in mice for antiviral drug development. J. Neurovirol. 2015, 21, 43-55. [CrossRef] [PubMed]

16. Julander, J.G.; Smee, D.F.; Morrey, J.D.; Furuta, Y. Effect of T-705 treatment on western equine encephalitis in a mouse model. Antivir. Res. 2009, 82, 169-171. [CrossRef] [PubMed]

17. Logue, C.H.; Bosio, C.F.; Welte, T.; Keene, K.M.; Ledermann, J.P.; Phillips, A.; Sheahan, B.J.; Pierro, D.J.; Marlenee, N.; Brault, A.C.; et al. Virulence variation among isolates of Western equine encephalitis virus in an outbred mouse model. J. Gen. Virol. 2009, 90, 1848-1858. [CrossRef] [PubMed]

18. Nagata, L.P.; Hu, W.G.; Parker, M.; Chau, D.; Rayner, G.A.; Schmaltz, F.L.; Wong, J.P. Infectivity variation and genetic diversity among strains of Western equine encephalitis virus. J. Gen. Virol. 2006, 87, 2353-2361. [CrossRef] [PubMed]

19. Phillips, A.T.; Stauft, C.B.; Aboellail, T.A.; Toth, A.M.; Jarvis, D.L.; Powers, A.M.; Olson, K.E. Bioluminescent imaging and histopathologic characterization of WEEV neuroinvasion in outbred CD-1 mice. PLoS ONE 2013, 8, e53462. [CrossRef] [PubMed]

20. Phillips, A.T.; Schountz, T.; Toth, A.M.; Rico, A.B.; Jarvis, D.L.; Powers, A.M.; Olson, K.E. Liposome-antigen-nucleic acid complexes protect mice from lethal challenge with western equine encephalitis viruses. J. Virol. 2014, 88, 1771-1780. [CrossRef] [PubMed]

21. Honnold, S.P.; Mossel, E.C.; Bakken, R.R.; Fisher, D.; Lind, C.M.; Cohen, J.W.; Eccleston, L.T.; Spurgers, K.B.; Erwin-Cohen, R.; Bradfute, S.B.; et al. Eastern equine encephalitis virus in mice I: Clinical course and outcome are dependent on route of exposure. J. Virol. 2015, 29, 12-152. [CrossRef] [PubMed]

22. Raabe, O.G.; Al-Bayati, M.A.; Teague, S.V.; Raslot, A. Regional deposition of inhaled monodisperse coarse and fine aerosol particles in small laboratory animals. Ann. Occup. Hyg. 1988, 32, 53-63.

23. Menache, M.; Miller, F.; Raabe, O. Particle inhalability curves for humans and small laboratory animals. Ann. Occup. Hyg. 1995, 39, 317-328. [CrossRef]

24. Schlesinger, R.B. Comparative deposition of inhaled aerosols in experimental animals and humans: A review. J. Toxicol. Environ. Health 1985, 15, 197-214. [CrossRef] [PubMed]

25. Phillips, A.T.; Rico, A.B.; Stauft, C.B.; Hammond, S.L.; Tawfik, A.A.; Aboellail, T.A.; Tjalkens, R.B.; Olson, K.E. Entry sites of Venezuelan and Western equine encephalitis viruses in the mouse central nervous system following peripheral infection. J. Virol. 2016, 90, 5785-5796. [CrossRef] [PubMed]

26. Metcalf, T.U.; Griffin, D.E. Alphavirus-induced encephalomyelitis: Antibody-secreting cells and viral clearance from the nervous system. J. Virol. 2011, 85, 11490-11501. [CrossRef] [PubMed]

27. Burdeinick-Kerr, R.; Wind, J.; Griffin, D.E. Synergistic roles of antibody and interferon in noncytolytic clearance of Sindbis virus from different regions of the central nervous system. J. Virol. 2007, 81, 5628-5636. [CrossRef] [PubMed]

28. Binder, G.K.; Griffin, D.E. Interferon- $\gamma$-mediated sites specific clearance of alphavirus from CNS neurons. Science 2001, 293, 303-306. [CrossRef] [PubMed]

29. Levine, B.; Hardwick, J.M.; Trapp, B.D.; Crawford, T.O.; Bollinger, R.C.; Griffin, D.E. Antibody-mediated clearance of alphavirus infection from neurons. Science 1991, 254, 856-860. [CrossRef] [PubMed] 
30. Wang, Y.; Lobigs, M.; Lee, E.; Mullbacher, A. CD8 ${ }^{+}$T cells mediate recovery and immunopathology in West Nile virus encephalitis. J. Virol. 2003, 77, 13323-13334. [CrossRef] [PubMed]

31. Griffin, D.E.; Levine, B.; Tyor, W.; Ubol, S.; Despres, P. The role of antibody in recovery from alphavirus encephalitis. Immunol. Rev. 1997, 159, 155-161. [CrossRef] [PubMed]

32. Bennett, A.M.; Elvin, S.J.; Wright, A.J.; Jones, S.M.; Phillpotts, R.J. An immunological profile of Balb/c mice protected from airborne challenge following vaccination with a live attenuated Venezuelan equine encephalitis virus vaccine. Vaccine 2000, 19, 337-347. [CrossRef]

33. Wu, J.Q.H.; Barabe, N.D.; Chau, D.; Wong, C.; Rayner, G.R.; Hu, W.; Nagata, L.P. Complete protection of mice against a lethal dose challenge of Western equine encephalitis virus after immunization with an adenovirus-vectored vaccine. Vaccine 2007, 25, 4368-4375. [CrossRef] [PubMed]

34. Phillpotts, R.J.; O’Brien, L.; Appleton, R.A.; Carr, S.; Bennett, A. Intranasal immunization with defective adenovirus serotype 5 expressing the Venezuelan equine encephalitis virus E2 glycoprotein protects against airborne challenge with virulent virus. Vaccine 2005, 23, 1615-1623. [CrossRef] [PubMed]

35. Guyton, A.C. Measurement of the respiratory volumes of laboratory animals. Am. J. Physiol. 1947, 150, 70-77. [PubMed]

36. Wright, A.W.; Phillpotts, R.J. Humane endpoints are an objective measure of morbidity in Venezuelan Encephalomyelitis virus infection of mice. Arch. Virol. 1998, 143, 1-8. [CrossRef]

37. Reed, L.J.; Muench, H. A simple method of estimating fifty percent endpoints. Am. J. Epidemiol. 1938, 27, 493-497. [CrossRef]

38. Hicks, D.J.; Nunez, A.; Healy, D.M.; Brookes, S.M.; Johnson, N.; Fooks, A.R. Comparative pathological study of the murine brain after experimental infection with classical rabies virus and European bat lyssaviruses. J. Comp. Pathol. 2009, 140, 113-126. [CrossRef] [PubMed]

(C) Crown copyright (2017). This material is licensed under the terms of the Open Government Licence except where otherwise stated. To view this licence, visit (http://www.nationalarchives.gov.uk/doc/open-government-licence/version/3 or write to the Information Policy Team, The National Archives, Kew, London TW9 4DU, or email: psi@nationalarchives.gsi.gov.uk. 